\title{
A Methodology for Constructing Marginal Abatement Cost Curves for Climate Action in Cities
}

\author{
Nadine Ibrahim ${ }^{*}+{ }^{\dagger}$ and Christopher Kennedy ${ }^{\dagger}$ \\ Faculty of Applied Science and Engineering, University of Toronto, 35 St. George Street, Toronto, \\ ON M5S 1A4, Canada; christopher.kennedy@utoronto.ca \\ * Correspondence: nadine.ibrahim@mail.utoronto.ca; Tel.: +1-647-448-4111 \\ + These authors contributed equally to this work.
}

Academic Editor: Jukka Heinonen

Received: 1 January 2016; Accepted: 8 March 2016; Published: 23 March 2016

\begin{abstract}
As drivers of climate action, cities are taking measures to reduce greenhouse gas (GHG) emissions, which if left unabated pose a challenge to meeting long-term climate targets. The economics of climate action needs to be at the forefront of climate dialogue to prioritize investments among competing mitigation measures. A marginal abatement cost (MAC) curve is an effective visualization of climate action that initiates a technical and economic discussion of the cost-effectiveness and abatement potential of such actions among local leaders, policy makers, and climate experts. More commonly demonstrated for countries, MAC curves need to be developed for cities because of their heterogeneity, which vary in their urban activities, energy supply, infrastructure stock, and commuting patterns. The methodology for constructing bottom-up MAC curves for cities is presented for technologies that offer fuel switching and/or energy efficiencies, while considering technology lifetimes, city-specific electricity and fuel prices, and emission intensities. Resulting MAC curves are unique to every city, and chart the pathway towards low-carbon growth by prioritizing measures based on cost-effectiveness. A case study of Toronto's climate targets demonstrates the prioritization of select technologies. Leveraging MAC curves to support climate programs enables cities to strategically invest in financing climate action and designing incentives.
\end{abstract}

Keywords: cities; marginal abatement cost; greenhouse gas emissions; cost-effectiveness; abatement potential; Toronto; buildings; transportation; waste; energy supply

\section{Introduction}

The cost of climate action globally [1-4] reveals the financial burden of climate change that society will incur, and the numbers are alarming. The maximum estimated available funding in the future to mitigate climate change through the United Nations Framework Convention on Climate Change (UNFCCC) and other funds is $\$ 100$ billion per year [5], however, the capital investments needed globally to achieve greenhouse gas (GHG) emission reductions to maintain global warming below $2{ }^{\circ} \mathrm{C}$ are much bigger, and estimated between $\$ 350$ billion and $\$ 1.1$ trillion per year by 2030 [2]. The International Energy Agency [4] estimates similar global capital needs to address GHG emissions, and shows that investing in clean energy needs to double by 2020 , and would require $\$ 36$ trillion (35\%) more in investments from today to 2050 than under a scenario in which controlling emissions does not take priority, and represents $\$ 1$ trillion additional investment each year to 2050. Globally, countries are engaged in talks regarding new climate agendas and climate commitments, however, more locally, it is in cities at the forefront of climate action, where climate leaders work within the contexts of the practicality, technical feasibility and economic viability of strategies to reduce GHG emissions.

While cities currently account for over $67 \%$ of energy-related global greenhouse gases, which is expected to rise to $74 \%$ by 2030 [6], there is an increasing business potential associated with 
developing and maintaining low-carbon and zero-waste cities is estimated between $\$ 3$ trillion and $\$ 10$ trillion per year $[7,8]$. Because of these rising numbers, tackling climate action at the city-scale is more constructive to climate action planning than at the country-scale because of the capabilities for innovation, accountability of decision-makers and accessibility to policy instruments; and is more conducive than at the neighbourhood-scale due to the availability of financial resources to implement climate programs. The economics of GHG mitigation options and its financial implications for cities plays an important role in the choices of mitigation measures that are implemented today.

The challenge lies in the costing of mitigation alternatives which is widely missing from the discourse on mitigation, and currently in a form that is not readily used nor easily accessed by decision-makers such as homeowners, businesses and city leaders alike, to make informed decisions. Compounding that with the broad range of available options makes the task of planning and implementing mitigation evermore challenging for constrained budgets. One such opportunity to address these issues for cities is by constructing marginal abatement cost (MAC) curves that illustrate the economics of climate change mitigation measures by a visual representation showing their GHG abatement potentials as a function of GHG abatement costs, and placing mitigation measures in ascending order of cost-effectiveness.

Though MAC curves have been more commonly developed for countries, the case for cities is presented through this paper. The goal of this research is to develop a process that enables cities to incorporate the economics together with the technical merits of GHG mitigation in climate change planning practices by compiling and prioritizing mitigation measures. The objective is to develop a methodology for constructing MAC curves for cities to demonstrate a quantitative visualization of climate action. Making this methodology available in the literature is a contribution to the economics of climate change mitigation and through which the assumptions and nuances involved become apparent so that they can be considered. While the literature on MAC curves is growing, MAC curves for specific sectors and countries dominate the literature, whereas those for cities are just beginning to gain traction, though not in academic literature. MAC curves for cities differ from those developed for their national counterparts, because the parameters for costs, savings and GHG emission sources are heterogeneous across countries and therefore reflect generalized mitigation measures not necessarily amenable to cities, or reflecting the reality in cities. A MAC curve is unique to every city, and the package of mitigation options prioritized for one city, may be prioritized differently for another. In cities, the GHG profile, infrastructure stock, and climate programs are contextualized, thereby reflecting city-specific variables such as the expected population growth, emission intensity of the electricity supply, and commuting patterns. The application of MAC curves for cities underscores the need to include costed climate action in support of leveraging financial resources for the implementation of energy efficiency strategies and the adoption of low-carbon technologies. City MAC curves will drive climate policy discussions for cities' carbon futures for urban GHG emission sectors, and stakeholders within the city.

The paper begins with background on the progression of the MAC curves historically, in addition to their applications in GHG emission reductions. A critique of the MAC curve, along with its merits and shortcomings, and improvements to the existing approach are also reviewed. The methodology for developing city-specific MAC curves is described in a manner applicable to global cities, and includes equations for the quantification of GHG abatement costs (i.e., cost-effectiveness; $\$ / \mathrm{tCO}_{2}$ ) and GHG abatement potentials $\left(\mathrm{tCO}_{2}\right)$, as they apply to energy supply, buildings, transportation, and waste; and area demonstrated as a case study for Toronto's 2020 and 2050 climate targets using a selection of 50 technologies. Updates to climate action plans stem from the changing prioritization of mitigation measures based on the market uptake and diffusion of low-carbon technologies and their upfront capital costs going down. 


\section{Review of Marginal Abatement Cost Curves}

The initial use of MAC curves was demonstrated in sector-specific applications, not restricted to GHG emissions. MAC curves then evolved to their application for GHG emissions in countries, and on a global scale, and more recently emerging in cities.

\subsection{Early Conservation Supply Curves}

The concept behind the MAC curves (referred to in earlier literature as conservation supply curves) was developed to save crude oil consumption in the 1970s and to save electricity consumption in the 1980s $[9,10]$ in response to the oil price shocks of the 1970s. Abatement cost curves were applied to air pollutants and their impacts as a result of restructuring of national energy systems and energy conservation measures [11], waste reduction strategies in industry responding to tougher environmental regulations [12], and water availability to inform on the scale, costs and tradeoffs of solutions to water scarcity [13]. These curves are effective in communicating with policy-makers in a meaningful form that speaks to the economics and the technicalities of the impacts of abatement options. The communication is represented by the cost-effectiveness of alternative approaches ranked from lowest to highest cost-effectiveness to save on barrels of oil, kilowatt hours of electricity consumption, tons of $\mathrm{SO}_{x}$ in the atmosphere, kilograms of disposed waste, and cubic meters of water.

\subsection{Marginal Abatement Cost (MAC) Curves for Greenhouse Gas (GHG) Emissions}

As they apply to GHG emissions, MAC curves have been used in the climate policy domain. There are top-down models that generate a line showing a cost-effectiveness trend line relative to abatement potential [14]; and bottom-up models, which are constructed using a number of mitigation measures that are placed to form steps. MAC curves, as we know them today, showing the placement of options as steps in a continuum (also known as a bottom-up model), were popularized by McKinsey \& Company [15] where they were developed for GHG mitigation in 15 countries (Greece, Poland, Russia, Israel, India, Belgium, Brazil, China, Switzerland, Czech Republic, Sweden, Australia, US, UK and Germany), and more recently, the World Bank's Energy Sector Management Assistance Program (ESMAP) [16] showed mitigation options in six countries of emerging economies (Brazil, China, India, Indonesia, Mexico, South Africa) to identify the path towards low-carbon growth. Other MAC curves commissioned for countries have been developed for the Netherlands [17], Ireland [18], and Germany [19], which also referred to them as cost potential curves in which they were presented by differentiating by residential, commercial, public and industry sectors, and their relevant end uses. A smaller scale statewide MAC was developed for California [20], and a larger regional-scale MAC was developed for the European Union [21]. Ellerman and Decaux [22] used MAC curves to analyze post-Kyoto $\mathrm{CO}_{2}$ emissions trading for Annex $\mathrm{B}$ countries, and to demonstrate the advantages and the distribution of gains from emissions trading.

Global MAC curves are very few, yet all point toward conclusions that greater mitigation efforts are required, and that the costs will be large, but that the savings will largely compensate for upfront capital investments. Global MAC curves have been developed by the International Energy Agency [6] for 2050; McKinsey \& Company [23] for 2030, in addition a global curve in response to the financial crisis' effects on carbon economics [15], and by Akashi and Hanaoka [24] for 2050. On a global scale, the Working Group III to the Fifth Assessment Report of the Intergovernmental Panel on Climate Change $[25,26]$ listed technology-specific cost and performance parameters that determined levelized cost of electricity for the energy supply sector, and the levelized cost of conserved carbon for mitigation options in the transport, industry, and agriculture, forestry and other land use (AFOLU) sectors, however the costing approach is not directly comparable to abatement costs on MAC curves.

MAC curves have been beneficial in the climate policy context for GHG emission sectors in that they demonstrated the cost-effectiveness within and among sectors. Examples include abatement cost curves in the building sector in the US for end use technologies [27]. Also, in the US, MAC 
curves were constructed to compare transportation strategies among other sector-specific mitigation strategies [28,29], and the water-energy nexus was analyzed using an environmental abatement cost (EAC) curve showing the lifecycle economic efficiency of the potential for conserving both energy and water resources in California [30]. Energy and transportation technologies for small and medium enterprises were analyzed in Belgium [31].

\subsection{Emerging MAC Curves for Cities}

To the best of our knowledge at the time of writing, cities that have constructed MAC curves responding to their climate targets are London [32], Leeds City Region [33], New York City [34], Hongqiao Region of the Changning District of Shanghai [8,35], and Melbourne [36]. London explored abatement potentials for buildings, transport, energy, water and waste and showed their implications on the individuals, businesses, city and national level. Melbourne developed a MAC curve for energy supply, buildings (both commercial and residential), transport (including freight) and waste. New York developed a MAC curve for building sector interventions, and in Hongqiao 58 technologies across sectors were assessed. The effectiveness realized by the use of MAC curves as a communication strategy, and as a policy tool have been evidenced in cities.

\subsection{An Evaluation of MAC Curves}

The merits and shortcomings of MAC curves have been analyzed in the literature, where the merits are mostly in their application while their shortcomings are primarily in the methodologies used in their making. Nuances in the methodologies used for their construction have also been critiqued [37-39].

\subsubsection{Merits and Methodological Improvements}

Benefits of the MAC curves as they apply to climate discussions are in the visualization of comparable mitigation measures that demonstrate the economics as well as the technical merits of reducing GHG emissions. The comparison of mitigation measures within and among sectors is possible because of the technological details presented. The prioritization by cost-effectiveness stimulates climate policy discussions focused on the investment opportunities that make a MAC curve an effective tool to leverage climate financing. The potential of MAC curves can be in guiding climate policy, realizing the impact of policy options that may not bear upfront costs but contribute to the GHG abatement efforts, examining where new technological implementation fits along the abatement spectrum; and comparing new technologies relative to pre-existing ones.

Improvements on the MAC curve and using them for innovative approaches to prioritize and select mitigation options are demonstrated for GHG reduction options in buildings and water utilities. The works of Ürge-Vosrsatz and Novikova [40] and Ürge-Vosrsatz et al. [41,42] for world buildings identifies the most promising mitigation options in terms of cost-effectiveness and magnitude of emission reduction, and demonstrate how these differ by region. The inclusion of life-cycle costs yields different prioritizations than with the consideration of first costs alone were demonstrated for water utilities in comparison to transportation and building options [30]. Research in the timing of options with lower abatement costs (i.e., cheap) and lower abatement potentials (i.e., deep) are explored to assist with decisions on options to implement and in which order $[43,44]$ using an intertemporal optimization for European climate targets. The speed at which mitigation measures are implemented to curb GHG emissions recognizes that optimal strategies to reach a short-term target depends on longer-term targets, which helps avoid carbon-intensive lock-in effects.

\subsubsection{Shortcomings and Limitations of Application}

Owing to the complexity of climate change mitigation and the diversity of stakeholders involved, MAC curves have not been void of criticism relating to the construction of the individual measures and the presentation of the overall MAC curve. Criticism of the MAC curves pertains to issues of 
transparency, practicality, external costs, and assumptions [38]. Because MAC curves are based on the individual assessment of mitigation measures, and are considered to contain proprietary information, the data pertaining to the cost and emission saving potential are not available publicly. According to Ackerman and Bueno [45], McKinsey \& Company has recently made the data behind their MAC curves available to corporations and governments through its Climate Desk database, which contains data collected for over 100 technology and policy options covering 11 economic sectors, with separate estimates of abatement costs and technical potential in 21 world regions.

Kesicki and Ekins [37] caution against the limitations of the MAC curves in terms of the method of generating and presenting the cost curve where the methodologies omit ancillary benefits of GHG emission abatement, treat uncertainty in a limited manner, exclude intertemporal dynamics and lack the transparency behind their assumptions. MAC curves are developed for a snapshot in time, beyond which they cannot be applied to reflect future scenarios unless an updated version is produced. They are compiled using technological measures, which means behavioural and operational measures (assumed at zero cost) have largely not been included which results in them not being part of the prioritization mix. Individual mitigation measures need to be compared relative to a reference technology, typically not identified, and largely subjective, involves uncertainty and lacks transparency. Costing of the mitigation alternatives requires knowledge of the wide-variability of market prices for capital costs of technologies, fuel source, fuel consumption, fuel switch (if applicable), efficiency factors, and design life. The calculation of costs and GHG reductions are sensitive to discount rate, and fuel and electricity prices. MAC curves have so far not included ancillary benefits, such as health costs and costs of environmental damages, and have not included the time to implementation for large projects with lead-time for construction. Abatement potentials include assumptions of the business-as-usual scenario of GHG emissions growth, and depend largely on the model used for GHG emission forecasting. GHG abatement potentials include assumptions regarding their current adoption, market trends, technological diffusion, and future use. Path dependency has not been factored in the methodology, so the order in which measures are implemented can only be considered after-the-fact and has no bearing on the cost-effectiveness of successive mitigation alternatives.

Kesicki and Strachan [38] identify ways to overcome current limitations in the generation of MAC curves, which involve the inclusion of ancillary benefits, better representation of uncertainties and representation of cumulative emission abatement to address time-related interactions, in addition to a systems approach to capture interactions among mitigation options. Some measures have costs incurred by one entity and benefits and savings incurred by another, which makes it a complicated representation of costs and savings, though it embodies the essence of climate change being truly a team effort, because every stakeholder has a role to play.

\subsubsection{MAC Curves Influence on Policy}

Being regarded as an effective policy tool for governments, practical applications of MAC curves have influenced policy and facilitated the decarbonization efforts by bringing the economics of climate change to the decision-making process. Examples include those developed by McKinsey and Company $[15,23]$ to quantify the technical and economic feasibility of different target levels, and to propose reduction options to pursue to meet their targets. For the countries with MAC curves developed by ESMAP [16], their tool offers comparisons among mitigation options and estimates of the incentives required to make such options attractive for the private sector by calculations of breakeven carbon prices; and for governments in assessing the investments needed in their move towards low carbon growth. In response to rising energy bills, the Leeds City Region have used MAC curves to make investment decisions in energy efficiency and low carbon options as a way to shield itself against the implications of energy price increases, and where the MAC curve has shown that decarbonization is possible in achieving a 40\% reduction in emissions by 2022 [33]. Drafting a roadmap to zero net emissions in Melbourne, the city has identified from the MAC curve outputs that $86 \%$ of the identified opportunities deliver financial savings through reduced energy costs in residential and commercial 
buildings, primarily through energy efficiency, and as such can maintain current emissions levels in 2020 despite growth in population and economic activity [36]. Similarly, Shanghai municipal and Changning District governments have developed MAC curves in their transition to a low-carbon city, in which they have identified in ways to increase the share of non-fossil fuels (renewable energy and nuclear) in primary energy [35].

\section{Results}

Using the proposed MAC curve methodology for cities, two MAC curves are constructed for the City of Toronto's climate targets in 2020 and 2050, respectively. Mitigation measures on the MAC curves represent the urban sectors of GHG emissions that are compatible with those reported in the city's GHG inventory, and include technologies that reduce electricity and natural gas consumption in buildings, and gasoline and diesel for transportation options. A total of fifty mitigation measures are compiled to represent six technologies in energy supply (for renewable and non-renewable sources), 36 technologies in residential and commercial/institutional buildings (for space heating, space cooling, water heating, lighting, and appliances, in addition to options to reduce the demand on grid electricity), five measures in passenger vehicles and freight trucks, and three measures for waste from residential and commercial/institutional sources.

The inputs and details used in the calculation of the parameters for the construction of the MAC curves are presented in Supplementary Material. A discount rate of 5\% is applied, and a sensitivity analysis to discount rate is included in Table S1 in Supplementary Material. Tables S2-S9 in Supplementary Material make available all costing information and abatement estimations, and make transparent all assumptions, as a way to overcome the common critique of the lack of transparency inherent in MAC curves.

Toronto's 2020 climate target (30\% of 1990 levels) calculated at $19.1 \mathrm{MtCO}_{2}$ requires a GHG abatement of $6 \mathrm{MtCO}_{2}$, where Figure 1 shows that the city is set to meet its 2020 target at a GHG abatement cost priced at $\$ 70 / \mathrm{tCO}_{2}$. Figure 2 corresponds to Toronto's 2050 target ( $80 \%$ of 1990 levels), which is calculated at $5.5 \mathrm{MtCO}_{2}$, and shows that given the current rate of adoption and diffusion of the mitigation technologies for the city's existing climate policies and programs, Toronto will only be halfway towards achieving the $49 \mathrm{MtCO}_{2}$ reduction. The cost-effectiveness of mitigation measures range from -658 to $2384 \$ / \mathrm{tCO}_{2}$. Implications for Toronto's carbon future from the MAC curves for 2020 and 2050 timeframes contribute to the climate action dialogue, which is currently underway at the local government level, and offer guidance for future climate policies and mitigation strategies for the city to pursue or expedite their implementation.

The benefits of assessing the type and magnitude of climate action using MAC curves and prioritizing mitigation measures in cities in the context of a climate planning process are realized when integrating climate action with GHG inventories and budgets. The quantitative basis, both technically and economically, for climate action offered by MAC curves are most effective in substantiating the choices of GHG mitigation alternatives among policy- and decision-makers.

The future of prospective MAC curves for cities would show the sectors of activities and stakeholders, in addition to technologies that offer savings, and to whom these savings would be realized. Programs in cities that aim to reduce emissions would be visualized on the MAC curve for which the opportunities for the biggest investments, savings, and GHG reductions are placed in comparison to other opportunities of potentially lesser impact. For local governments, it would be advantageous to pursue more of and intensify the mitigation interventions that make large contributions to GHG reductions; and increase the marketing efforts through policy and targeted communication for measures that offer households and businesses more savings. 


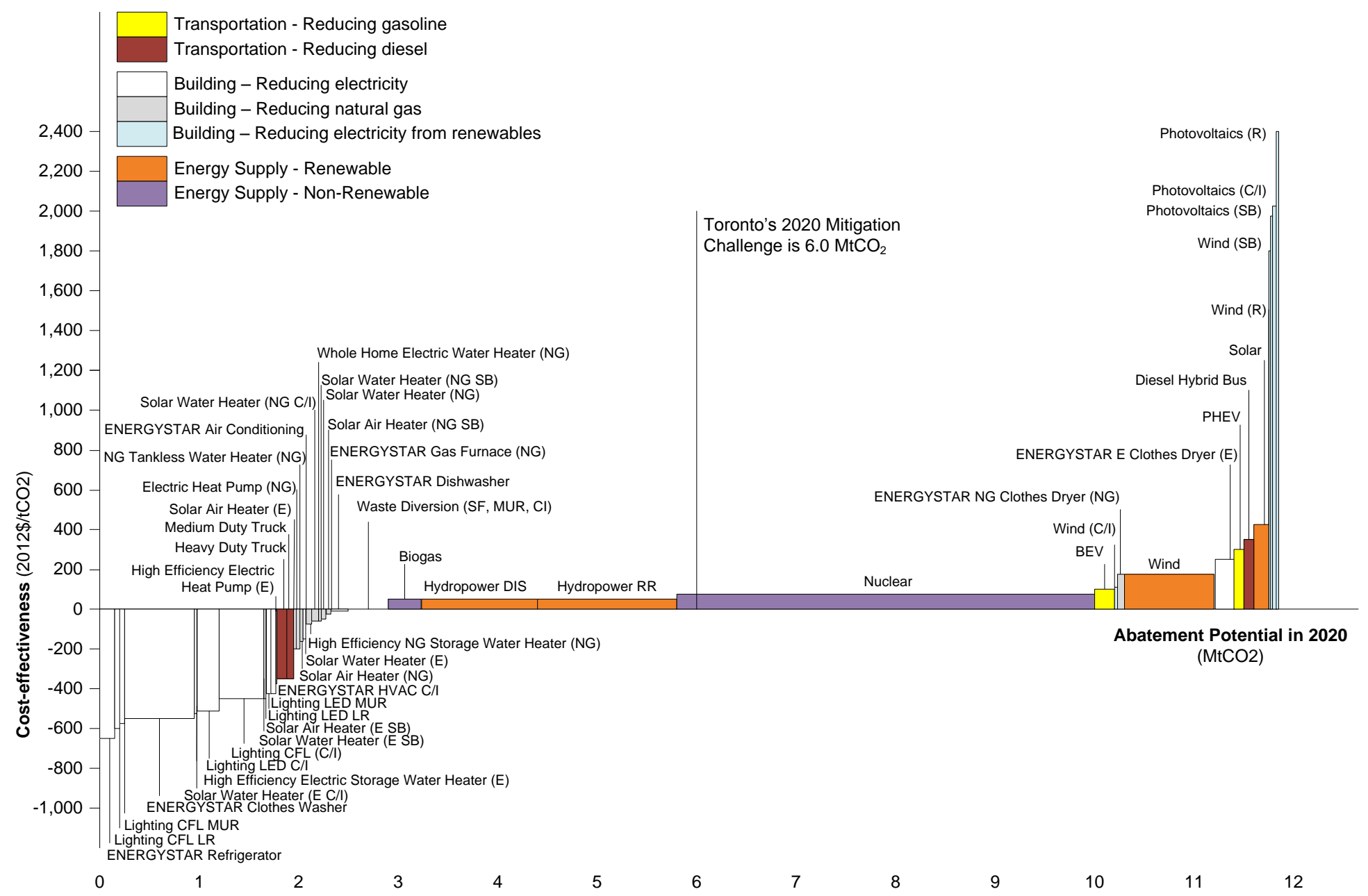

Figure 1. Toronto 2020 marginal abatement cost (MAC) curve showing mitigation measures by sector and a marginal abatement cost of $70 \$ / \mathrm{tCO}_{2}$ for the city's 2020 target $(\mathrm{R}=$ Residential, $\mathrm{LR}=$ Low-rise, $\mathrm{MUR}=$ Multi-unit residential, $\mathrm{SF}=$ Single-family, SB = Small Business, $\mathrm{C} / \mathrm{I}=\mathrm{Commercial} /$ Institutional, $\mathrm{NG}=\mathrm{Natural}$ gas, $\mathrm{E}=$ Electricity). 


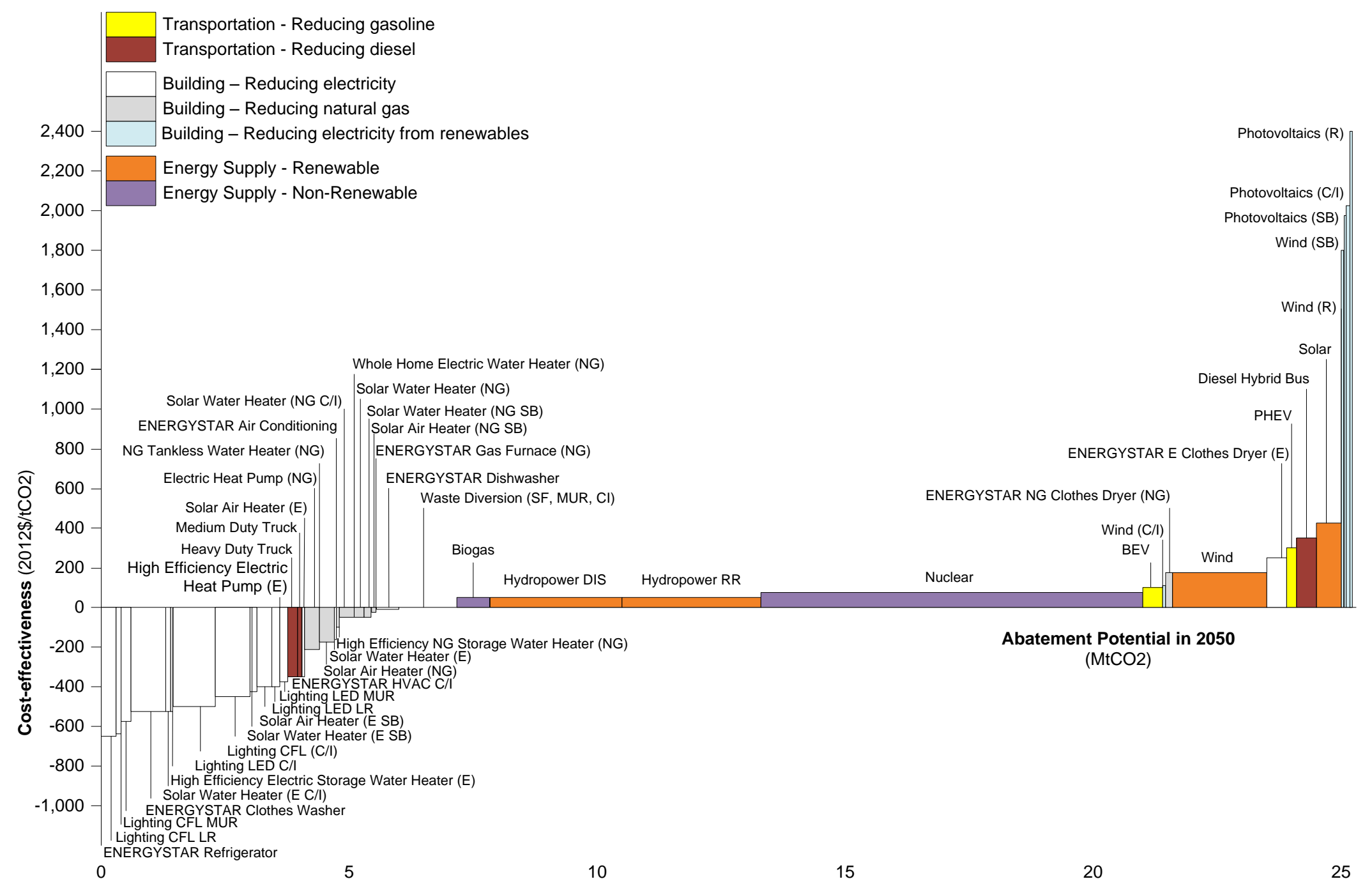

Figure 2. Toronto $2050 \mathrm{MAC}$ curve showing mitigation measures by sector $(\mathrm{R}=$ Residential, $\mathrm{LR}=$ Low-rise, MUR = Multi-unit residential, $\mathrm{SF}=\mathrm{Single-family,}$ $\mathrm{SB}=$ Small Business, $\mathrm{C} / \mathrm{I}=$ Commercial $/$ Institutional, $\mathrm{NG}=$ Natural gas, $\mathrm{E}=$ Electricity) . 


\section{Discussion}

The merits of MAC curves lie in visually demonstrating climate mitigation efforts in a city. The MAC curve methodology involves initially a compilation of a city's climate mitigation policies and programs, followed by a quantitative analysis of the technical and economic dimensions of each of the mitigation measures considered. The MAC curve allows a presentation of measures by sector to show the contribution and resulting abatement among city activities, by energy source to define fossil-based versus renewables to show decarbonization efforts, and by stakeholder to show financial commitments to implement measures. As an effective visual, the MAC curve makes it possible to engage decision-makers and city leaders in a climate dialogue focused on climate action from multiple perspectives simultaneously. Technically, abatement potentials can guide the adoption of newer technologies; economically, the cost-effectiveness of measures supports the need for financial incentives required for measures with large upfront capital costs; and politically, the impact of climate policies can be quantitatively calculated and demonstrated.

A MAC curve displays its most potential if it is handled as an evolving visual decision-making tool where it is updated regularly in light of new strategies that have an impact on city activities and emissions. Methodological issues can continue to be refined in the construction of the MAC curve and in determining the inputs to the MAC curve calculations; however, do not lessen its contribution in showing the prioritization of measures. Non-technological options, that are assumed to bear no costs, appear on the zero line on the MAC curve. Behavioural measures, and those indicative of operational efficiency, as they become included in future analysis, will appear on the zero line, and are distinctly placed in a way that separates the measures that have net savings from those bearing net costs. Calculating the investments, savings, and reductions; and attributing each to their respective investor and beneficiary is a challenge because of the multiple stakeholders involved. Modeling the interactions among stakeholders, and the intertemporal relationships among measures could be the next improvement to the MAC curve.

The MAC curve could also be used as a monitoring and evaluation tool to track progress in the implementation of measures to determine faster or slower GHG reduction rates, and the corresponding reasons to replicate successful strategies and modify or expedite more delayed ones. Pathways for implementation of the measures are not determined, which is a common limitation of the MAC curve, though the prioritization can be used as a guide for action. One such way to accommodate the order of implementation of the measures and the interactions among measures is particularly relevant to measures that are prioritized after an energy supply intervention (which affects the emission intensity of the electricity), in a way that reduces the GHG intensity of the electricity consumption utilized by the measures running on electricity.

Assumptions need to be documented, and uncertainty in the inputs need to be determined and calculated in sensitivity analyses, as the MAC curve continues to be updated and refined to reflect realities in cities. Uncertainty could be examined if sensitivity analyses are applied to inputs such as technology costs, energy prices, GHG intensity of electricity, adoption rates and market penetration of technology, existing infrastructure stock, and existing implementation of measures, and discount rate. There is innovative yet limited work done on upstream emissions; however, this aspect of the bottom-up model can be built over time in alignment with data collection [46]. The calculations are developed for $\mathrm{CO}_{2}$ emissions, but could also include other greenhouse gases particularly relevant when mitigation to industrial activities is applicable and of interest to cities.

\section{Methodology for Constructing a Bottom-Up MAC Curve}

The MAC curve for GHG mitigation measures is a visualization that is constructed using a bottom up approach that compiles mitigation measures in a step function to enable a prioritization based on cost-effectiveness. The curve is not actually a curve, but rather steps, along a continuum that captures the costs and benefits of low-carbon technologies and energy-efficiency in the form of a prioritization plot of mitigation measures ranked from lowest to highest cost-effectiveness. The more 
comprehensive and useful a cost-effectiveness indicator can be in prioritizing mitigation measures is contingent upon accounting for the costs and benefits of such measures to the extent possible. MAC curves are developed for a target year, typically a year in the future representing climate target commitments. The methodology presented here takes the merits of MAC curves, and overcomes some of the shortcomings, while applying it to cities. All assumptions are made transparent, and costing is obtained from local sources in the city, unless it cannot be obtained, then a country source, or a global technology cost is used, making it as much as possible a city-specific costing. Technology options are included (though as a general methodology, policy and operational options could potentially be added). This is an attempt to develop a general methodology, so that when applied to cities consistently, makes the comparability among MAC curves possible, and from which cities can draw parallels among mitigation measures.

Calculating the cost-effectiveness of each of the mitigation measures requires quantifying two parameters: marginal abatement cost, or cost-effectiveness $\left(\$ / \mathrm{tCO}_{2}\right)$ and abatement potential $\left(\mathrm{tCO}_{2}\right)$, as shown in Figure 3. Mitigation measures are placed from lowest to highest cost-effectiveness, where each measure is represented as a step along the MAC curve plot. The $y$-axis is the marginal abatement cost of GHG emissions $\left(\$ / \mathrm{tCO}_{2}\right)$, where the height of each step represents the net present cost (incremental costs less benefits) of the mitigation measure per ton of $\mathrm{CO}_{2}$ reduction over the lifetime of the measure. The $x$-axis is the abatement potential of GHG emissions $\left(\mathrm{tCO}_{2}\right)$, where the width of each step represents the GHG abatement potential of a mitigation measure during the analysis period. The area of the step is the total marginal investment cost for the $\mathrm{CO}_{2}$ abatement potential achieved by the mitigation measure.

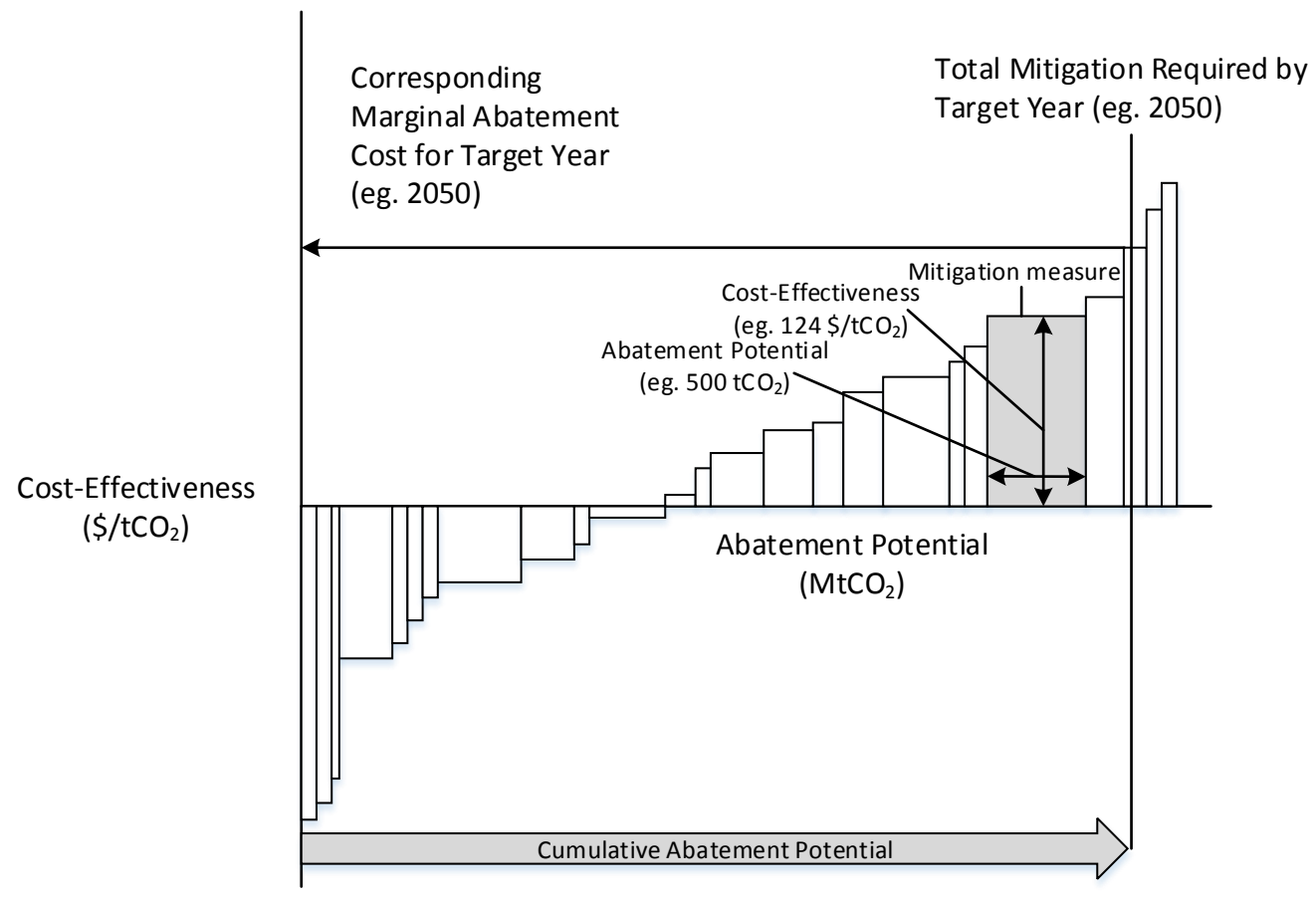

Figure 3. Marginal Abatement Cost (MAC) curve components.

The cumulative emission reductions achieved by the prioritized mitigation measures is obtained by adding the abatement potential of each of the mitigation measures plotted. The target emission reduction is a point on the $x$-axis, where all mitigation measures leading to that point forms the GHG abatement required to achieve the climate target. Measures that fall below zero on the $y$-axis reflect a negative cost-effectiveness, which means the measures offer net savings (benefits exceed costs). Measures that appear above zero, reflect a positive cost-effectiveness, which means the measures have costs that exceed their benefits. 
The costs and benefits of mitigation measures are analyzed relative to business-as-usual, employing a reference technology, hence marginal, for which the costs and fuel consumption are "frozen". Costs include capital costs, and where applicable, operating costs relevant to energy use, and does not include transaction costs and taxes. Benefits are limited to cost savings associated with reductions in energy consumption, and do not include co-benefits such as avoided environmental damages, health costs, and other social problems and inconveniences.

The calculations of the cost-effectiveness and abatement potential of mitigation measures are summarized in Equations (1)-(9). The cost-effectiveness, $\mathrm{CE}_{\mathrm{MM}}\left(\$ / \mathrm{tCO}_{2}\right)$, is calculated using data on incremental costs and energy savings achieved by the mitigation measure, and the emissions savings over its lifetime, as in Equation (1):

$$
\mathrm{CE}_{\mathrm{MM}}=\frac{\mathrm{NPC}_{\mathrm{INC}, \mathrm{MM}}}{\mathrm{E}_{\mathrm{MM}}}
$$

where:

$\mathrm{CE}_{\mathrm{MM}}=$ Cost effectiveness of the mitigation measure over the lifetime of the measure in $2012 \$$ per ton of $\mathrm{CO}_{2}$ reduction, $\$ / \mathrm{tCO}_{2}$;

$\mathrm{NPC}_{\mathrm{INC}, \mathrm{MM}}=$ Net present cost of the incremental costs and benefits of the mitigation measure over the lifetime of the measure, $\$$; and

$\mathrm{E}_{\mathrm{MM}}=\mathrm{GHG}$ emissions avoided during the lifetime of the measure, $\mathrm{tCO}_{2}$.

The net present costs, $\mathrm{NPC}_{\mathrm{INC}, \mathrm{MM}}$, include capital costs and net benefits over the lifetime of the technology, as in Equation (2):

$$
\mathrm{NPC}_{\mathrm{INC}, \mathrm{MM}}=\mathrm{K}_{\mathrm{INC}, \mathrm{MM}}+\sum_{\mathrm{t}=0}^{\mathrm{L}} \mathrm{B}_{\mathrm{INC}, \mathrm{MM}}(\mathrm{t})
$$

where: $\mathrm{K}_{\mathrm{INC}, \mathrm{MM}}$ is the incremental capital cost of the mitigation measure; and $\mathrm{B}_{\mathrm{INC}, \mathrm{MM}}(\mathrm{t})$ is the incremental net benefits, evaluated as annual financial savings by the mitigation measure, over its lifetime, where the benefits are taken to be the savings achieved by reduction in energy consumption relative to a reference technology. Only financial savings are considered as benefits in this equation. Other co-benefits undoubtedly exist, but are not monetized and therefore not considered in the model. All costs are obtained from various sources and are converted to 2012 dollars.

Incremental (or marginal) costs, $\mathrm{K}_{\mathrm{INC}, \mathrm{MM}}$, and benefits, $\mathrm{B}_{\mathrm{INC}, \mathrm{MM}}(\mathrm{t})$, are calculated relative to a reference technology which is selected and compared against, as shown in Equations (3)-(6).

$$
\mathrm{K}_{\mathrm{INC}, \mathrm{MM}}=\mathrm{K}_{\mathrm{MM}}-\mathrm{K}_{\mathrm{REF}}
$$

where: $\mathrm{K}_{\mathrm{MM}}$ is the capital cost of the mitigation measure; and $\mathrm{K}_{\mathrm{REF}}$ is the capital cost of the reference technology (if any).

Annual operating costs and savings are included throughout the lifetime of the technology, and are handled with a discount factor, resulting in a summation denoted as net present cost of the mitigation measure calculated, as follows:

$$
\mathrm{B}_{\mathrm{INC}, \mathrm{MM}}(\mathrm{t})=\sum_{\mathrm{t}=0}^{\mathrm{L}}\left(\mathrm{C}_{\mathrm{INC}, \mathrm{MM}}(\mathrm{t})-\mathrm{S}_{\mathrm{INC}, \mathrm{MM}}(\mathrm{t})\right) \times \frac{(1+i)^{\mathrm{L}}-1}{\mathrm{i}(1+i)^{\mathrm{L}}}
$$

where:

$\mathrm{C}_{\mathrm{INC}, \mathrm{MM}}(\mathrm{t})=$ Annual incremental costs of the operations of the mitigation measure, at time $\mathrm{t}$, over its lifetime, \$;

$\mathrm{S}_{\mathrm{INC}, \mathrm{MM}}(\mathrm{t})=$ Annual savings, evaluated as financial savings due to reduced energy consumption of the mitigation measure, over its lifetime, $\$$;

$i=$ discount rate, $\%$;

$\mathrm{L}=$ Lifetime of mitigation measure (estimated as the design life of the technology), in years. 
Similarly, incremental annual operating costs are calculated as follows:

$$
\mathrm{C}_{\mathrm{INC}, \mathrm{MM}}(\mathrm{t})=\left[\mathrm{C}_{\mathrm{MM}}(\mathrm{t})-\mathrm{C}_{\mathrm{REF}}(\mathrm{t})\right]
$$

where: $C_{M M}(t)$ is the annual operation cost of the mitigation measure; and $C_{R E F}(t)$ is the annual operation cost of the reference technology.

Incremental annual savings realized by reducing energy consumption where the equation for the calculation of savings is set up to include measures that involve fuel efficiency or fuel switching, is calculated as follows:

$$
\mathrm{S}_{\mathrm{INC}, \mathrm{MM}}(\mathrm{t})=\left[\mathrm{EC}_{\mathrm{BE}, \mathrm{REF}}(\mathrm{t})-\mathrm{EC}_{\mathrm{BE}, \mathrm{MM}}(\mathrm{t})\right] \times \mathrm{p}_{\mathrm{BE}}-\mathrm{EC}_{\mathrm{AE}, \mathrm{MM}}(\mathrm{t}) \times \mathrm{p}_{\mathrm{AE}}
$$

where:

$\mathrm{EC}_{\mathrm{BE}, \mathrm{REF}}=$ Annual energy consumption of baseline energy by the reference technology, in GJ;

$\mathrm{EC}_{\mathrm{BE}, \mathrm{MM}}=$ Annual energy consumption of the baseline energy of the mitigation measure, in GJ;

$\mathrm{EC}_{\mathrm{AE}, \mathrm{MM}}=$ Annual energy consumption of alternate energy (due to fuel switching) of the mitigation measure, in GJ;

$\mathrm{p}_{\mathrm{BE}}=$ Unit price of energy (for baseline energy), in $\$ / \mathrm{GJ}$ (constant in the analysis); and

$\mathrm{p}_{\mathrm{AE}}=$ Unit price of energy (for alternate energy), in $\$ / G J$ (constant in the analysis).

GHG emission reduction achieved by the mitigation measure, $\mathrm{E}_{\mathrm{MM}}$, during its lifetime is calculated as shown in Equation (7), and also allows for fuel efficiency and fuel switching.

$$
\mathrm{E}_{\mathrm{MM}}=\left[\left(\left(\mathrm{EC}_{\mathrm{BE}, \mathrm{REF}}-\mathrm{EC}_{\mathrm{BE}, \mathrm{MM}}\right) \times \mathrm{EF}_{\mathrm{BE}}\right)-\left(\mathrm{EC}_{\mathrm{AE}, \mathrm{MM}} \times \mathrm{EF}_{\mathrm{AE}}\right)\right] \times \mathrm{L}
$$

where: $\mathrm{EF}_{\mathrm{BE}}$ and $\mathrm{EF}_{\mathrm{AE}}$ are emission factors of energy used as baseline or alternate, respectively, in $\mathrm{tCO}_{2} / \mathrm{GJ}$ (or the equivalent $\mathrm{kgCO}_{2} / \mathrm{MJ}$ for gasoline, diesel, natural gas, fuel oil; and $\mathrm{gCO}_{2} / \mathrm{kWh}$ for electricity).

Calculations to determine the abatement potential of each mitigation measure are less straightforward. Assumptions regarding abatement potential require knowledge of the business-as-usual scenario, upon which the magnitude of the reductions can be estimated. A model to determine current and forecasted infrastructure stock is required as a prerequisite. Estimations of abatement potential are based on how much of the measure is currently being implemented and how much more can be implemented in the future. Abatement potential assumes either a fraction of the infrastructure stock in future years will implement the technology, or an increase of the technology annually during the timeframe of the analysis. GHG emission abatement is calculated based on the infrastructure stock in a target year, as shown in Equation (8).

$$
\mathrm{A}_{\mathrm{GHG}, \mathrm{MM}}=\frac{\mathrm{E}_{\mathrm{MM}}}{\mathrm{L}} \times n_{\mathrm{TARGET}} \times \mathrm{U}_{\mathrm{MM}} \times \mathrm{S}_{\mathrm{MM}}
$$

where:

$\mathrm{A}_{\mathrm{GHG}, \mathrm{MM}}=\mathrm{GHG}$ abatement potential achieved by the mitigation measure which is implemented by the "eligible" infrastructure stock in the target year $\left(\mathrm{tCO}_{2}\right)$; ("eligible" stock is the amount of stock for which the mitigation measure is applicable and does not include the total infrastructure stock);

$n_{\text {TARGET }}=$ Number of years to target year of the climate commitment for emission reductions, and represents the analysis period up to the target year. For example, if the year 2012 is the beginning of the analysis, therefore $n=8$ for 2020, and $n=38$ for 2050 .

$\mathrm{U}_{\mathrm{MM}}=$ Units of the mitigation measure in the infrastructure stock (e.g., one appliance per household, 1 passenger vehicle per 20,000 VKT)

$\mathrm{S}_{\mathrm{MM}}=$ Infrastructure stock to which the mitigation measure is eligible (i.e., applicable to), measured in number of households for residential buildings and residential waste sectors, GFA $\left(\mathrm{m}^{2}\right)$ for commercial buildings and commercial waste sectors, VKT $(\mathrm{km})$ in passenger vehicles, 
buses and freight transportation, and kWh for electricity consumption. Note: existing technology penetration is subtracted from the eligible stock.

Once both variables, $\mathrm{A}_{\mathrm{GHG}, \mathrm{MM}}$ and $\mathrm{CE}_{\mathrm{MM}}$, are calculated for all mitigation measures, the measures are ranked from lowest to highest cost-effectiveness to construct the MAC curve. A vertical line crossing the $x$-axis at the point where the cumulative abatement is equivalent to the GHG reduction target shows all the measures preceding the vertical line, which is required for implementation to reach that GHG climate target. A horizontal line crossing the $y$-axis that coincides with the target GHG reduction is used to determine the $\mathrm{CO}_{2}$ abatement cost (for emission trading scenarios, for example). Cumulative GHG abatement by mitigation measures is calculated as shown in Equation (9).

$$
\mathrm{A}_{\mathrm{GHG}, \text { Cumulative }}=\sum_{\mathrm{MM}=1}^{\mathrm{N}} \mathrm{A}_{\mathrm{GHG}, \mathrm{MM}}
$$

where: $N=$ number of prioritized mitigation measures added to achieve the GHG emission reduction target, $\mathrm{E}_{\mathrm{MIT}}$, to meet the mitigation challenge that achieves the climate targets. Examples of $\mathrm{E}_{\mathrm{MIT}}$ are business-as-usual emissions relative to $80 \%$ of 1990 levels by 2050 .

Assumptions involved in the calculations and analysis of the MAC curve include the following:

1. Reference technology is selected for comparison, and in some cases mitigation measures do not replace a technology, but rather are additional, in which case, a reference technology does not apply.

2. Industry costs are used for costing technologies; where cost estimates that are city-specific when and where available are used, but country and global costing data are used in the event of their absence at the city scale.

3. Average capital cost of technology is used.

4. Existing technology penetration, or policy adoption is assumed from existing city programs, if available.

5. Abatement is assumed to follow the status quo, i.e., existing uptake of the technology.

6. Planned abatement takes city program projections into account.

7. Savings only include financial savings from reduced fuel or energy consumption, and is the only benefit considered.

8. Co-benefits are not considered in the analysis.

9. Some policy options are assumed to have no cost, but result in emission savings.

10. Information is obtained from publicly available documents where possible.

Inputs necessary to the MAC curve calculations include the following:

1. Capital cost of mitigation measures, and reference technologies are converted to 2012\$.

2. Operations and maintenance (O\&M) costs.

3. Discount rate (assumed 5\%).

4. Energy source.

5. Emission factors for energy sources.

6. Emissions intensity of the power supply.

7. Electricity and fuel prices.

8. Stock of residential, commercial, transportation and waste in target years based on an emissions forecasting model.

9. Lifetime of technologies for reference technology and mitigation measure, and reconciled where different. 


\section{Conclusions}

The methodology for marginal abatement cost curves is developed to be applicable to global cities, and is made available to encourage its adoption among cities. The approach to constructing the MAC curve for cities requires initially a compilation of mitigation programs and policies in the city, and in broader climate programs that have an impact on mitigation activities within the city, with a look to those planned in the future by having a vision of anticipated future progress of low-carbon technologies [47]. Once constructed, a city MAC curve can continue to be updated and refined by adding more mitigation measures, modifying assumptions to better reflect reality, and revising abatement potentials based on the speed of technological diffusion and market penetration. Updates to MAC curves need to be as frequently and as regularly developed, to be consistent with updates to city GHG inventories, to guide an inform climate action in cities.

Supplementary Materials: The following are available online at www.mdpi.com/1996-1073/9/4/227/s1.

Acknowledgments: This study was partially funded by Natural Sciences and Engineering Research Council of Canada (NSERC).

Author Contributions: Nadine Ibrahim and Christopher Kennedy conceived and developed the methodology; Nadine Ibrahim demonstrated the methodology for a case study; Nadine Ibrahim and Christopher Kennedy analyzed the data; Christopher Kennedy contributed data inputs; Nadine Ibrahim wrote the paper.

Conflicts of Interest: The authors declare no conflict of interest. The founding sponsors had no role in the design of the study; in the collection, analyses, or interpretation of data; in the writing of the manuscript, and in the decision to publish the results.

\section{Abbreviations}

The following abbreviations are used in this manuscript:

GHG Greenhouse gas

MAC Marginal Abatement Cost

METRO Managing Emission Targets and Reduction Options

\section{References}

1. World Bank. World Development Report 2010: Development and Climate Change. Available online: http:/ / siteresources.worldbank.org/INTWDR2010/Resources/5287678-1226014527953/WDR10 -Full-Text.pdf (accessed on 4 June 2015).

2. World Bank. Towards a Partnership for Sustainable Cities. Urbanization Knowledge Partnership. 2012. Available online: http:/ /www.urbanknowledge.org/smartsustainablecities.html (accessed on 7 June 2015).

3. McKinsey Global Institute. Urban World: Mapping the Economic Power of Cities; McKinsey \& Company: London, UK, 2011.

4. IEA (International Energy Agency). Energy Technology Perspectives 2012: Pathways to a Clean Energy System; International Energy Agency: Paris, France, 2012.

5. Hoornweg, D.; Sugar, L.; Trejos-Gomez, C.L. Cities and greenhouse gas emissions: Moving forward. Environ. Urban. 2011, 23, 207-227. [CrossRef]

6. IEA (International Energy Agency). Energy Technology Perspectives 2008: Scenarios and Strategies to 2050; International Energy Agency: Paris, France, 2008.

7. Cities and Climate Change: Responding to an Urgent Agenda. World Bank. 2011. Available online: https://openknowledge.worldbank.org/bitstream/handle/10986/2312/626960PUB0Citi000public00BOX 361489B.pdf?sequence=1 (accessed on 7 June 2015).

8. World Bank. The Low Carbon City Development Program (LCCDP) Guidebook. A systems Approach to Low Carbon Development in Cities; The World Bank, DNV KEMA Energy and Sustainability, 2012. Available online: http://siteresources.worldbank.org/INTURBANDEVELOPMENT/Resources/ 336387-1371610171995/LCCDP-Guidebook_Draft-for-Consultation.pdf (accessed on 4 June 2015).

9. Meier, A.; Rosenfeld, A.; Wright, J. Supply curves of conserved energy for California's residential sector. Energy 1982, 7, 347-358. [CrossRef] 
10. Jackson, T. Least-cost greenhouse planning supply curves for global warming abatement. Energy Policy 1991, 19, 35-46. [CrossRef]

11. Rentz, O.; Haasis, H.D.; Jattke, A.; Ru, P.; Wietschel, M.; Amann, M. Influence of energy-supply structure on emission-reduction costs. Energy 1994, 19, 641-651. [CrossRef]

12. Beaumont, N.J.; Tinch, R. Abatement cost curves: A viable management tool for enabling the achievement of win-win waste reduction strategies? J. Environ. Manag. 2004, 71, 207-215. [CrossRef] [PubMed]

13. Addams, L.; Boccaletti, G.; Kerlin, M.; Stuchtey, M. Charting Our Water Future-Economic Frameworks to Inform Decision-Making; 2030 Water Resources Group, McKinsey \& Company: New York, NY, USA, 2009.

14. Kesicki, F. Decomposing Long-Run Carbon Abatement Cost Curves-Robustness and Uncertainty. Ph.D. Thesis, University College London, London, UK, 2012. Available online: http://discovery.ucl.ac.uk/ 1338584/1/1338584.pdf (accessed on 7 June 2015).

15. McKinsey \& Company. Greenhouse Gas Abatement Cost Curves. 2010. Available online: http:/ /www.mckinsey.com/ client_service/sustainability/latest_thinking/greenhouse_gas_abatement_cost_curves (accessed on 2 June 2015).

16. ESMAP (Energy Sector Management Assistance Program). Low Carbon Growth Country Studies-Getting Started: Experience from Six Countries Low Carbon Growth Country Studies Program. Carbon Finance Assist, World Bank. 2012. Available online: http://sdwebx.worldbank.org/climateportalb/doc/ ESMAP/KnowledgeProducts/Low_Carbon_Growth_Country_Studies_Getting_Started.pdf (accessed on 3 June 2015).

17. Blok, K.; Worrell, E.; Cuelenaere, R.; Turkenburg, W. The cost effectiveness of $\mathrm{CO}_{2}$ emission reduction achieved by energy conservation. Energy Policy 1993, 21, 656-667. [CrossRef]

18. Sustainable Energy Ireland. Ireland's Low-Carbon Opportunity: An Analysis of the Costs and Benefits of Reducing Greenhouse Gas Emissions. 2009. Available online: http://www.seai.ie/Publications/ Renewables_Publications_/Low_Carbon_Opportunity_Study/Irelands_Low-Carbon_Opportunity.pdf (accessed on 5 June 2015).

19. Wuppertal Institute. Options and Potentials for Energy End-Use Efficiency and Energy Services. Wuppertal Institute for Climate, Environment and Energy. 2006. Available online: http://epub.wupperinst.org/ frontdoor/index/index/docId/5015 (accessed on 7 June 2015).

20. Sweeney, J.; Weyant, J. Analysis of Measures to Meet the Requirements of California's Assembly Bill 32. Precourt Institute for Energy Efficiency, Stanford University. 2008. Available online: http://web.stanford.edu/group/peec/cgi-bin/docs/policy/research/September\%2027\%202008\%20Discussion $\% 20$ Draft $\% 20-\% 20$ Analysis $\% 20$ of $\% 20$ Measures $\% 20$ to $\% 20$ Meet $\% 20$ the $\% 20$ Requirements $\% 20$ of $\% 20$ Californias \%20Assembly\%20Bill\%2032.pdf (accessed on 5 June 2015).

21. Blok, K.; de Jager, D.; Hendriks, C.; Kouvaritakis, N.; Mantzos, L. Economic Evaluation of Sectoral Emission Reduction Objectives for Climate Change: Top-down Analysis of Greenhouse Gas Emission Reduction Possibilities in the EU. Contribution to a Study for DG Environment, European Commission by Ecofys Energy and Environment, AEA Technology Environment and National Technical University of Athens. 2001. Available online: http://ec.europa.eu/environment/enveco/climate_change/pdf/top_down_analysis.pdf (accessed on 5 June 2015).

22. Ellerman, A.D.; Decaux, A. Analysis of Post-Kyoto $\mathrm{CO}_{2}$ Emissions Trading Using Marginal Abatement Curves. MIT's Joint Program on the Science and Policy of Global Change. 1998. Available online: http:/ / test2-globalchange.mit.edu/files/document/MITJPSPGC_Rpt40.pdf (accessed on 5 June 2015).

23. McKinsey \& Company. Pathways to a Low-Carbon Economy. Version 2 of the Global Greenhouse Gas Abatement Cost Curve. 2009. Available online: http:/ /www.mckinsey.com/client_service/sustainability/ latest_thinking/pathways_to_a_low_carbon_economy (accessed on 4 June 2015).

24. Akashi, O.; Hanaoka, T. Technological feasibility and costs of achieving a $50 \%$ reduction of global GHG emissions by 2050: Mid- and long-term perspectives. Sustain. Sci. 2014, 7, 139-156. [CrossRef]

25. IPCC (Intergovernmental Panel on Climate Change). Climate Change 2014: Mitigation of Climate Change. Contribution of Working Group III to the Fifth Assessment Report of the Intergovernmental Panel on Climate Change; Edenhofer, O.R., Pichs-Madruga, Y., Sokona, E., Farahani, S., Kadner, K., Seyboth, A., Adler, I., Baum, S., Brunner, P., Eickemeier, B., et al, Eds.; Cambridge University Press: Cambridge, UK; New York, NY, USA, 2014. Available online: https://www.ipcc.ch/pdf/assessment-report/ar5/wg3/ipcc_wg3_ar5_full.pdf (accessed on 7 June 2015). 
26. Annex III: Technology-Specific Cost and Performance Parameters, 2014. Available online: https://www.ipcc.ch/ pdf/assessment-report/ar5/wg3/ipcc_wg3_ar5_annex-iii.pdf (accessed on 7 June 2015).

27. Rubin, E.S.; Cooper, R.N.; Frosch, R.A.; Lee, T.H.; Marland, G.; Rosenfeld, A.H.; Stine, D.D. Realistic mitigation options for global warming. Science 1992, 257, 148-266. [CrossRef] [PubMed]

28. Lutsey, N.P. Prioritizing Climate Change Mitigation Alternatives: Comparing Transportation Technologies to Options in Other Sectors. Ph.D. Thesis, University of California Davis, Davis, CA, USA, 2008. Available online: http://www.its.ucdavis.edu/research/publications/publication-detail/?pub_id=1175 (accessed on 7 June 2015).

29. Lutsey, N.; Sperling, D. Greenhouse gas mitigation supply curve for the United States for transport versus other sectors. Transp. Res. Part D 2009, 14, 222-229. [CrossRef]

30. Stokes, J.R.; Hendrickson, T.P.; Horvath, A. Save water to save carbon and money: Developing abatement costs for expanded greenhouse gas reduction portfolios. Environ. Sci. Technol. 2014, 48, 13583-13591. [CrossRef] [PubMed]

31. De Schepper, E.; Van Passel, S.; Lizin, S.; Achten, W.M.J.; Van Acker, K. Cost-efficient emission abatement of energy and transportation technologies: Mitigation costs and policy impacts for Belgium. Clean Technol. Environ. Policy 2014, 16, 1107-1118. [CrossRef]

32. Sustainable Urban Infrastructure: London Edition-A View to 2025. Available online: https:/ /www.swe.siemens.com/ italy/web/citta_sostenibli/ricerche/Documents/SustainableUrbanInfrastructure-StudyLondon.pdf (accessed on 4 June 2015).

33. Gouldson, A.; Kerr, N.; Topi, C.; Dawkins, E.; Kuylenstierna, J.; Pearce, R. The Economics of Low Carbon Cities: A Mini-Stern Review for the Leeds City Region. Available online: http://www.the-lep.com/ LEP/media/LCR-Corporate/Research\%20and\%20publications/Green\%20Economy/Leeds-City-RegionMini-Stern.pdf?ext=.pdf (accessed on 1 February 2016).

34. City of New York. New York City's Pathway to Deep Carbon Reductions, Mayor's Office of Long-Term Planning and Sustainability, New York. 2013. Available online: http://s-media.nyc.gov/ agencies/planyc2030/pdf/nyc_pathways.pdf (accessed on 4 June 2015).

35. World Bank. Applying Abatement Cost Curve Methodology for Low-Carbon Strategy in Changning District, Shanghai. 2013. Available online: https://openknowledge.worldbank.org/bitstream/handle/ 10986/16710/840680ESW0whit00City0Summary0Report.pdf?sequence=1 (accessed on 4 June 2015).

36. Climate Works Australia. Melbourne's Zero Net Emissions Strategy, Update 2014. Available online: https://www.melbourne.vic.gov.au/Sustainability/CouncilActions/Documents/zero_net_emissions _update_2014.pdf (accessed on 3 June 2015).

37. Kesicki, F.; Ekins, P. Marginal abatement cost curves: A call for caution. Clim. Policy 2012, 12, $219-236$. [CrossRef]

38. Kesicki, F.; Strachan, N. Marginal abatement cost (MAC) curves: Confronting theory and practice. Environ. Sci. Policy 2011, 14, 1195-1204. [CrossRef]

39. Ward, D.J. The failure of marginal abatement cost curves in optimising a transition to a low carbon energy supply. Energy Policy 2014, 73, 820-822. [CrossRef]

40. Ürge-Vorsatz, D.; Novikova, A. Potentials and costs of carbon dioxide mitigation in the world's buildings. Energy Policy 2008, 36, 642-661. [CrossRef]

41. Ürge-Vorsatz, D.; Koeppel, S.; Mirasgedis, S. Appraisal of policy instruments for reducing buildings' $\mathrm{CO}_{2}$ emissions. Build. Res. Inf. 2007, 35, 458-477. [CrossRef]

42. Ürge-Vorsatz, D.; Novikova, A.; Köppel, S.; Boza-Kiss, B. Bottom-up assessment of potentials and costs of $\mathrm{CO}_{2}$ emission mitigation in the buildings sector: Insights into the missing elements. Energy Effic. 2009, 2, 293-316. [CrossRef]

43. Vogt-Schilb, A.; Hallegatte, S. Policy Research Working Paper 5803, When Starting with the Most Expensive Option Makes Sense: Use and Misuse of Marginal Abatement Cost Curves, World Bank, Sustainable Development Network, Office of the Chief Economist. 2011. Available online: http://www-wds.worldbank.org/external/default/WDSContentServer/WDSP/IB/2011/09/21/000158349 _20110921094422/Rendered/PDF/WPS5803.pdf (accessed on 7 June 2015).

44. Vogt-Schilb, A.; Hallegatte, S. Marginal abatement cost curves and the optimal timing of mitigation measures. Energy Policy 2014, 66, 645-653. [CrossRef] 
45. Ackerman, F.; Bueno, R. Use of McKinsey Abatement Cost Curves for Climate Economics Modeling, Stockholm Environment Institute. 2011. Available online: http:/ /www.sei-international.org/ mediamanager/documents/Publications/Climate/sei-workingpaperus-1102.pdf (accessed on 7 June 2015).

46. Lutsey, N.; Sperling, D. America's bottom-up climate change mitigation policy. Energy Policy 2008, 36, 673-685. [CrossRef]

47. Reinventing the City: Three Prerequisites for Greening Urban Infrastructure. Available online: http://www.wwf.se/source.php/1481769/WWF_Low_Carbon_Cities_2012.pdf (accessed on 7 June 2015).

(c) 2016 by the authors; licensee MDPI, Basel, Switzerland. This article is an open access article distributed under the terms and conditions of the Creative Commons by Attribution (CC-BY) license (http://creativecommons.org/licenses/by/4.0/). 